\title{
revista
}

tempos e espacos em educacão https://doi.org/10.20952/revtee.v12i31.11466

Recebido em 06.06.2019 | Aceito em 07.08.2019| Publicado em 11.11.2019.

\section{O Pronera como política pública educacional do campo: contextos e contradições}

\author{
Arlete Ramos dos Santos* \\ Mauro dos Santos Carvalho ${ }^{* *}$
}

\section{Resumo:}

O objetivo deste artigo é mostrar que o Programa Nacional de Educação na Reforma Agrária (PRONERA) foi implementado na Universidade Estadual do Sudoeste da Bahia (UESB) como uma política pública de educação do campo, por intermédio dos atores governamentais e não governamentais. Utilizou-se como metodologia, a relação existente entre os atores/sujeitos investigados na pesquisa, ressaltando as reivindicações da sociedade civil em prol de uma educação pública que fizesse frente às contradições impostas pela sociedade capitalista. Foi utilizado o método de estudo de caso, juntamente com as contribuições de algumas categorias do Materialismo Histórico Dialético (MHD). Os resultados alcançados com este trabalho demonstraram que o Pronera/UESB, enquanto política pública, cumpriu plenamente sua função social relacionada aos preceitos pedagógicos e acadêmicos, porém, não cumpriu sua função social em relação ao despertar e ao processo formativo dos atores/sujeitos beneficiários relacionados à ruptura dos fenômenos de ordem social, política, cultural e econômica.

Palavras-Chave: Educação do Campo; Política Pública; Pronera.

\footnotetext{
* Universidade Estadual do Sudoeste da Bahia. Vitória da Conquista, Bahia, Brasil. E-mail: arlerp@hotmail.com. Orcid: https://orcid.org/0000-0003-0217-3805

* Universidade Estadual do Sudoeste da Bahia. Vitória da Conquista, Bahia, Brasil. E-mail: mauro@uesb.edu.br. Orcid: https://orcid.org/0000-0003-2172-0245.
} 


\title{
Pronera as an educational public policy of rural areas: contexts and contradictions
}

\begin{abstract}
The objective of this article is to show how the National Program of Education in the Agrarian Reform (Pronera) was implemented at the State University of Bahia Southwest (UESB) as a public policy of rural education through governmental and non - governmental actors. The relationship between the actors / subjects investigated in the research was used as a methodology, highlighting the demands of civil society for a public education that faced the contradictions imposed by capitalist society. Case-study and quantitative-qualitative methods were used as a tool in the analyzes and evaluations carried out, along with the contributions of some categories of Dialectical Historical Materialism (MHD). The results obtained with this work showed that Pronera / UESB, as public policy, fully fulfilled its social function related to pedagogical and academic precepts, but did not fulfill its social function in relation to the awakening and formative process of the actors / beneficiary subjects related to the phenomena of social, political, cultural and economic order. Keywords: Field Education; Public Policy; Pronera.
\end{abstract}

\section{El pronera como política pública educativa del campo: contextos y contradiciones}

\section{Resumen}

El objetivo de este artículo es mostrar cómo el Programa Nacional de Educación en la Reforma Agraria (Pronera) fue implementado en la Universidad Estadual del Sudoeste de Bahía (UESB) como una política pública de educación del campo por intermedio de los actores gubernamentales y no gubernamentales. Se utilizó como metodología la relación existente entre los actores / sujetos investigados en la investigación, resaltando las reivindicaciones de la sociedad civil en pro de una educación pública que hiciera frente a las contradicciones impuestas por la sociedad capitalista. Para esta investigación, se utilizó los métodos de estudio de caso y cuantitativos como herramienta en los análisis y evaluaciones realizadas, junto con las contribuciones de algunas categorías del Materialismo Histórico Dialéctico (MHD). Los resultados alcanzados con este trabajo demostraron que el Pronera / UESB, en cuanto política pública, cumplió plenamente su función social relacionada con los preceptos pedagógicos y académicos, sin embargo, no cumplió su función social en relación al despertar y proceso formativo de los actores / sujetos beneficiarios relacionados ruptura de los fenómenos de orden social, político, cultural y económico.

Palabras clave: Educación del Campo; Política Pública; Pronera. 


\section{Introdução}

O Programa Nacional de Educação na Reforma Agrária - Pronera foi concebido e implementado pelo Governo Federal no ano de 1998, por intermédio da Portaria no 10 , de 16 de abril do referido ano. Posteriormente, tal Programa foi incorporado à estrutura administrativa do Instituto Nacional de Colonização e Reforma Agrária - INCRA, por meio da Portaria no 837, de 30 de agosto de 2001 e um novo Manual de Operações foi reeditado. Em conformidade com o Manual de Operações do Pronera (2004), constitui-se como objetivo principal deste, o fortalecimento da educação nas áreas e localidades formadas por assentamentos da Reforma Agrária, com o objetivo de estimular o desenvolvimento de projetos educacionais direcionados para os sujeitos beneficiários (jovens e adultos) que residem nestas áreas, através do oferecimento de cursos de Educação de Jovens e Adultos (EJA), com ênfase no Ensino Fundamental e em outras modalidades de ensino, como os cursos de Nível Médio com integração em uma área técnica específica, além de cursos de Pós-Graduação Latu e Stricto Sensu.

Cabe destacar que o modelo de gestão do Pronera é tripartite e envolve a participação do Governo Federal, por intermédio do INCRA, das Instituições de Ensino Superior (IES) públicas e privadas, sem fins lucrativos, dos movimentos sociais e sindicais vinculados ao campo, como o Movimento dos Trabalhadores Rurais Sem Terra (MST) e a Federação dos Trabalhadores na Agricultura (FETAG). Assim, estes grupos têm a função de apresentar as demandas dos alunos que irão se submeter ao processo de seleção nestas IES.

A Universidade Estadual do Sudoeste da Bahia (UESB), objeto da nossa pesquisa de Mestrado, é parceira dos projetos do Pronera desde o ano de 2001 e propiciou a formação e capacitação de muitos jovens e adultos provenientes de diversas áreas contempladas com assentamentos da Reforma Agrária do Estado da Bahia até o ano de 2013, nos cursos de Educação de Jovens e Adultos (EJA), nas modalidades de Alfabetização e Escolarização e Ensino Médio Integrado ao Técnico para os cursos de Agropecuária, Agente Comunitário de Saúde, Técnico em Enfermagem e Gestão Agrícola, totalizando quatro mil e setecentos e noventa e dois (4.792) alunos atendidos (CARVALHO, 2018). As considerações, análises e dados discutidos ao decorrer deste trabalho representam um recorte da pesquisa realizada no ano de 2018, utilizando-se de metodologias de abordagem qualitativa (entrevistas semiestruturadas) e quantitativa (questionários estruturados) que se complementaram nas análises, tendo como limite temporal o período compreendido entre 2004 a 2013.

As análises e resultados apresentados neste artigo evidenciam a importância da implantação e execução do Pronera na UESB como política pública de educação, além de sua reverberação direta e indireta na vida dos sujeitos envolvidos no processo, evidenciando também os aspectos contraditórios do Programa, em relação a sua implementação em uma sociedade capitalista e suas nuances em relação às redes de políticas públicas propostas para o referido Programa, pelos atores governamentais. 


\section{As políticas públicas e sua relação com o Pronera}

As políticas públicas podem ser definidas como um elenco característico de ações promovidas pelos atores governamentais, com objetivos de produzirem resultados específicos em diversas áreas na arena social, educacional, saúde, cultura, etc. Peters (1986) define política pública como o somatório das atividades dos governos, que atuam de forma direta ou por intermédio de ações delegadas que possam influenciar diretamente na vida dos cidadãos. As políticas públicas quando projetadas e formuladas são traduzidas em programas, pesquisas e projetos, que devem ser implementados e avaliados pelos atores governamentais que analisam a sua execução e avaliação.

Políticas educacionais, a exemplo do Pronera, representam um campo específico institucionalizado e de construção das demandas e afirmações dos sujeitos do campo como área de conhecimento, em processo já consolidado como realidade sócio-política merecedora de investigação constante no tocante aos seus resultados, desde a implantação e implementação até o processo avaliativo.

Os convênios institucionais firmados entre a UESB e o INCRA para implementar o Pronera, representaram a materialização dessas políticas públicas educacionais, na medida em que as relações entre entes públicos de esferas distintas concretizaram as teorias e propostas assinaladas pelo Estado, advindas das demandas apresentadas pelos movimentos sociais, como forma de promover mudanças em uma parcela da sociedade do campo, marginalizada e excluída do processo de ensino-aprendizagem.

Dentro desta ótica, na esfera das políticas públicas educacionais a nível Federal, o Pronera, junto à UESB, sempre se pautou em executar seus projetos em um regime de parceria, através dos diversos convênios já executados por esta Instituição de Ensino Superior (IES), objetivando proporcionar aos sujeitos beneficiados (alunos), não somente a transmissão de ensinamentos acadêmicos e pedagógicos por parte dos docentes que atuaram nos diversos cursos já realizados, mas também, a compreensão das contradições da sociedade capitalista nas suas práticas pedagógicas hegemônicas, transmutadas em políticas educacionais inerentes às classes dominantes.

\section{Carvalho (2018, p. 33), afirma a esse respeito que}

Neste sentido, a universidade constitui o lócus privilegiado para sistematizar e produzir o conhecimento das várias ciências e da cultura universal, definindo prioridades e ações no contexto histórico, cultural e social na qual está inserida. Conquanto, a universidade não possua o poder de propiciar as mudanças reivindicadas pela sociedade, a relativa autonomia que ela possui, consente em abrigar o livre pensar e estabelecer perspectivas pedagógicas, culturais e filosóficas na sustentação do seu cotidiano.

Objetivando mostrar a importância do Pronera executado pela UESB, o pesquisador optou pelo método de Estudo de Caso, com metodologia quali-quantitativa, cujos instrumentos de coleta de dados foram questionários e entrevistas semiestruturadas, respectivamente, para os três grupos de atores pesquisados (equipe técnica, professores representando a UESB e os sujeitos beneficiários que representam os movimentos sociais parceiros nos convênios pactuados), com questões de ordem administrativa, pedagógica, acadêmica, social. política e econômica. 
Objetivando também evidenciar e referendar os resultados do Estudo de Caso proposto, o pesquisador utilizou categorias do Materialismo Histórico Dialético - MHD, no intuito de compreender a realidade apresentada, apoiada na inquirição dos sujeitos envolvidos na pesquisa (LUKÁCS, 2004).

\section{Conexões entre políticas públicas, o Pronera/UESB e as categorias do MHD}

De acordo com Lukács (2010, p. 228 apud MASSON, 2012, p. 03) “[...] as categorias são como princípios de formação lógicos ou gnosiológicos no interior do conhecimento, mas como determinações do próprio ser [...]”. Tal afirmativa referenda o fato de que os fatores objetivos que perpassam no Estudo de Caso, proposto na pesquisa, representam as realidades concretas dos atores partícipes em que as categorias de totalidade do MHD do método marxista, compreendidas como universalidade, particularidade e singularidade, consideram no seu arcabouço teórico e prático as análises no seu caráter qualitativo e quantitativo, de forma conexa e geral das políticas educacionais implementadas, a exemplo do Pronera na UESB (CARVALHO, 2018).

Referindo-se ao marco conceitual acima apresentado, na acepção de Chasin (1988), deve-se considerar que o Estudo de Caso proposto e realizado na pesquisa foi pautado em um momento histórico representado por uma totalidade específica, através da parceria estabelecida entre três atores com características acadêmicas, políticas, sociais, econômicas e culturais distintas, em prol da execução de uma política educacional de governo e, posteriormente, de Estado. Neste contexto, tem-se que a universalidade, na acepção de categoria de totalidade do MHD, é marcada por diversos aspectos inerentes à sociedade capitalista representada pelo Estado. No Estudo de Caso abordado, a pesquisa versou também sobre os aspectos que nortearam as relações intrínsecas existentes entre a sociedade capitalista e seus agentes públicos, além de um projeto de educação do campo, transcorrendo pelos atores envolvidos na pesquisa e os cenários sociais internos e externos a estes em relação a esta sociedade, realçando também as reivindicações sociais dos sujeitos do campo relacionadas ao processo de educação que contemplasse esse processo dialético.

A partir da análise dos dados coletados nessa pesquisa, constatou-se que a categoria "particularidade" foi representada pela mediação existente no contexto histórico assinalado por meio dos atores governamentais partícipes dos convênios firmados com a UESB, a saber: o INCRA e a Coordenação Geral de Educação do Campo e Cidadania, responsáveis diretos pela gestão do Pronera. Paralelamente, a categoria "singularidade" foi representada na pesquisa mediante o Pronera, como política pública específica do Governo Federal.

A implementação do Pronera na UESB, representou o estabelecimento de uma política pública de educação para os atores (sujeitos) oriundos do campo, que refletiu diretamente em um movimento de contradição (categoria metodológica do MHD) em que os atores governamentais implementaram essa política pública educacional, impulsionados pelas expectativas e pressões dos atores sociais (movimentos sociais) que apresentaram suas demandas para o ator Universidade. Nesta perspectiva, Azevedo (2004) enfatiza que 
[...] as políticas públicas são definidas, implementadas, reformuladas ou desativadas com base na memória da sociedade ou do Estado em que têm lugar, que, por isso, guardam estreita relação com as representações sociais que cada sociedade desenvolve sobre si própria. Segundo essa ótica, as políticas públicas são ações que guardam intrínseca conexão com o universo cultural e simbólico, ou melhor dizendo, com o sistema de significações que é próprio de uma determinada realidade social. As representações sociais dominantes fornecem valores, normas e símbolos que estruturam as relações sociais e, como tal, se fazem presentes no sistema de dominação, atribuindo significados à definição social da realidade, que vai orientar os processos de decisão, formulação e implementação das políticas públicas. (AZEVEDO, 2004, p. 06).

A contradição como movimento dialético representou no presente Estudo de Caso a superação das demandas propostas pelos movimentos sociais e sindicais junto à UESB e aos atores governamentais (Estado), a ruptura de paradigmas existentes entre estes movimentos e os demais atores institucionais, e ainda observou-se que este movimento contraditório não representou na sua essência somente os interesses de uma classe, mas, acima de tudo, o poder de pressão impulsionado por forças democráticas que lutavam por um projeto político educacional consolidado na Instituição proposta para o Estudo de Caso.

A este núcleo de análise deve-se agregar as considerações propostas por Hermine (2013 apud CARVALHO, 2018, p. 74 e 75) na medida que o referido autor considera que

Adentrando nos pontos relacionados às contradições que se encontram atualizados nas políticas públicas educacionais para o campo, faz-se necessário abordar a categoria contradição. Esta categoria representa a unidade de luta dos contrários, tendo sua origem na realidade objetiva, partindo de diferenças não essenciais de caráter externo, que podem caracterizar-se como contradições, seguindo e chegando, posteriormente, ao estágio das diferenças essenciais. Em situações próprias, as diferenças essenciais revolvem aos contrários. Dando prosseguimento a esse movimento, os contrários adentram em conflito, em situação de interposição, tornando-se e condicionando a resolução das contradições. Essas diferenças, que possuem tendências e orientações às mudanças e progressões distintas, assumem aspectos de luta, transmutando-se em contrários nos seus métodos de desenvolvimento e, assim que as contradições são resolvidas, elas compõem um novo grupo de contradições.

Com base nessa colocação do autor, podemos refletir que os cursos do Pronera implementados e executados pela UESB representaram a consolidação das lutas e embates travados pelos movimentos sociais e sindicais parceiros nos projetos executados, em que o Estado foi chamado a garantir a continuidade de uma parceria já iniciada com os demais atores (UESB e movimentos), por meio da alocação de recursos financeiros e da sua contribuição à sociedade, resultando na manutenção das garantias dos povos do campo na sua formação acadêmica, pedagógica e social.

A partir dessas análises preliminares, evidencia-se o fato de que o Estudo de Caso abordou aspectos representativos inerentes a uma política pública de educação esboçada na sociedade capitalista, bem como as relações diretas e indiretas que envolveram os três atores objeto de investigação na pesquisa, ressaltando e enfatizando as demandas e cir- 
cunstâncias sociais, políticas e governamentais que pautaram a apreensão da realidade e suas múltiplas determinações do objeto de pesquisa lastreado no método do MHD.

\section{Compreensão das redes de políticas públicas da educação do campo no Estudo de Caso.}

De acordo com Carvalho et al. (2017, p. 02), é necessária a compreensão por parte dos agentes públicos que concebem as políticas públicas como a "[...] intensificação a setorialização, a compartimentalização, a segmentação da política governamental e a tecnificação das decisões que têm contribuído para ampliar a distância social entre parcelas da população", em meio aos atores que serão beneficiados com a implementação de tais políticas.

Nesse sentido, as ações do Pronera implementadas na UESB no período compreendido entre 2004 e 2013 representam a consolidação de um projeto político-pedagógico, capitaneado pelos movimentos sociais e sindicais parceiros, bem como os atores diretamente envolvidos na execução do projeto (professores, equipe técnica e beneficiários), em que a compreensão das Redes de Políticas Públicas é de suma importância para o entendimento de como os atores governamentais e não governamentais propuseram e implementaram o Pronera na UESB.

Conforme assevera Carvalho et al. (2017), a Rede de Políticas Públicas do Pronera/ UESB é constituída pelo Governo do Estado da Bahia, professores e equipe técnica, sendo que as ações propostas e executadas de caráter pedagógico e administrativo destes atores estão inseridas em um universo mais abrangente, a saber: Governo Federal, INCRA e Pronera, sendo que este último é representado pela Comissão Pedagógica Nacional (CPN) que é responsável direta pela análise e parecer dos projetos enviados pelas Instituições de Ensino Superior-IES de cada estado para eventuais convênios a serem firmados.

O modelo abaixo exposto representa o modelo de razão estratégica do Pronera/ UESB, em que as relações estratégicas internas e externas são evidenciadas pelos atores que fazem parte da arquitetura da rede.

Figura 1 - Rede de Políticas Públicas do Pronera/UESB

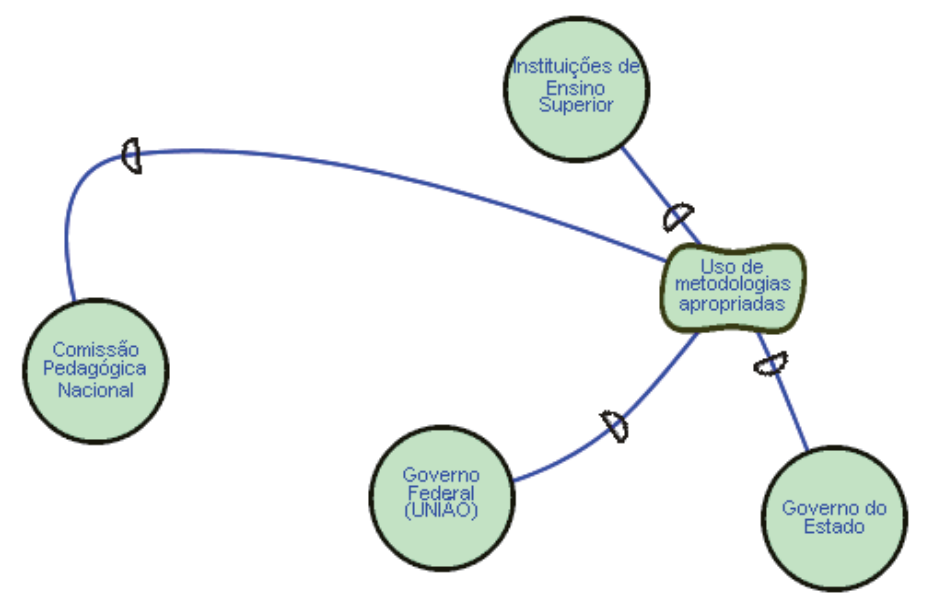

Fonte: Autoria própria, 2017. 
A Rede de Políticas Públicas do Pronera/UESB pode ser decomposta através das representações de todos aos atores que compuseram a estrutura elementar para que esse projeto político de educação do campo pudesse ser implantado, implementado e consolidado em uma IES como a UESB. A Figura 2 demonstra a constituição final da mencionada Rede com suas conexões e interligações entre todos os atores partícipes, diretos ou indiretos, para que o Pronera fosse consolidado na UESB.

Figura 2 - Dependência Estratégica entre os atores que compõem o Pronera/UESB

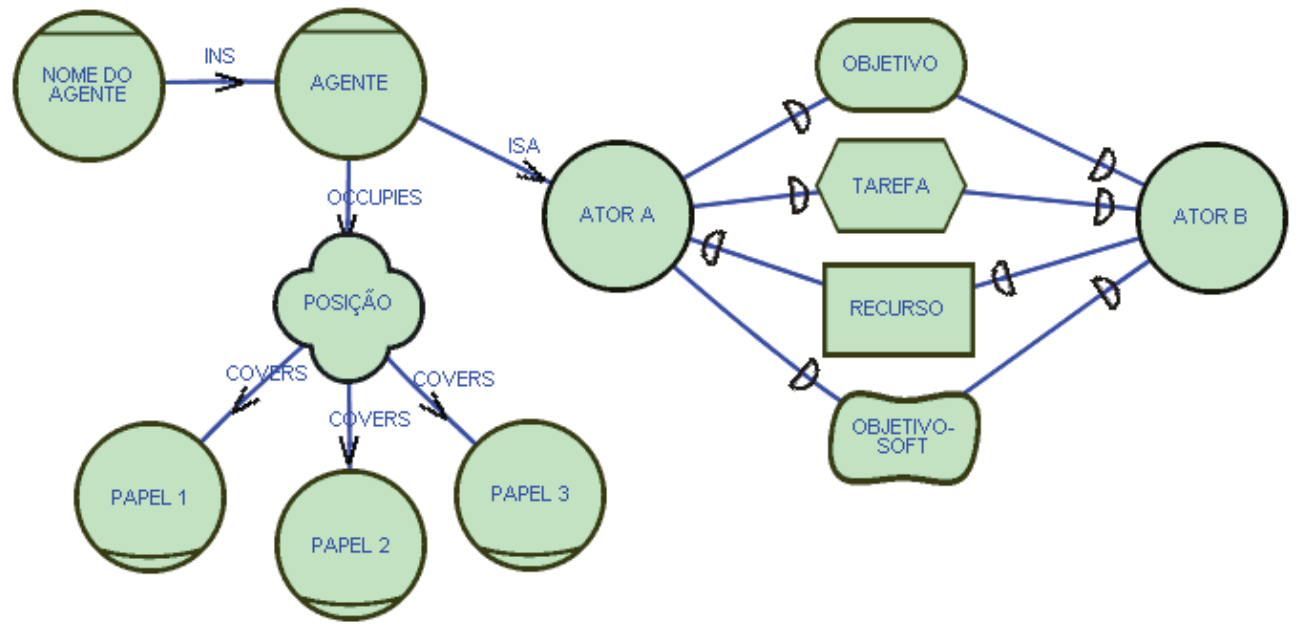

Fonte: Autoria própria, 2017.

A Figura 2 demonstra o papel do ator governamental do Governo Federal (Ator A) como pessoa jurídica legalmente constituída e representada pelo INCRA, por intermédio das suas Superintendências Regionais nos estados, sendo responsável pela gestão direta do Pronera em suas diversas facetas, a exemplo das normas de execução do Programa, alocação de recursos financeiros, instituição e funcionamento da Comissão Pedagógica Nacional - (CPN). O Ator "B" representa o Pronera e suas interconexões com as normativas do INCRA em consonância com os seus objetivos propostos, como política de educação do campo. As interconexões envolvendo os demais atores partícipes no modelo de dependência estratégica esboçado, são representadas pelo Papel "1", "2" e "3", tipificando os professores, equipe técnica e os beneficiários. Observa-se que estes Atores, apesar de estarem na "ponta" do processo, guardam relação de interdependência ( $\mathbf{D}$ ou $-\boldsymbol{G}$ ) direta e indireta com os demais Atores ("A" e "B"), sem os quais a execução de um projeto como o Pronera/UESB não seria possível. Os movimentos sociais e sindicais partícipes no projeto são representados pela denominação de Agentes Responsáveis, por apresentarem as demandas para os Atores "A" e " $B$ " (no exemplo do Pronera/UESB, as demandas foram apresentadas diretamente para o Ator "B", que é a UESB). Ainda na Figura 02, o Ator Agente também guarda relação de interdependência direta e indireta com os demais Atores.

Analisando as informações e definições teóricas aqui apresentadas acerca do projeto de educação do campo materializado no Pronera/UESB, é correto asseverar que as análises empreendidas a respeito das políticas públicas e sua modelagem, através da Rede de 
Política Pública do referido programa, representam as profusas relações presentes entre os atores governamentais e não governamentais empregadas para a compreensão dessa política pública argumentada neste Estudo de Caso.

Desse modo, à luz da análise do modelo de estrutura organizacional apresentado, pode-se verificar e constatar a forma de como as relações sociais são postas por meio da materialização de uma proposta de educação do campo de caráter pedagógico e direcionada na proposta de ensino-aprendizagem, com base na atuação direta e indireta dos atores governamentais e não governamentais, sendo que cada ator representa um papel estabelecido na Rede de atuação para essa proposta de educação do campo.

Molina (2006) estabelece que o projeto de educação do campo é constituído como meio dos instrumentos de luta dos contrários, manifestada diretamente aos projetos contra-hegemônicos da sociedade capitalista, em que os sujeitos do campo propõem e fazem parte de uma nova vertente histórica advinda de uma camada social excluída, que almeja prover a sua elevação cultural a partir de um projeto de educação direcionado para os sujeitos do campo. A educação do campo representa e evidencia, desse modo, a complexidade da realidade que perpassa pelas singularidades e ações dos atores sociais e governamentais, através dos seus diferentes projetos para consolidação de um projeto de educação coletivo, que é realizado por meio de projetos e programas singulares de educação do campo como o Pronera/UESB.

\section{Análise quantitativa e qualitativa do Estudo de Caso}

A análise quantitativa realizada no Estudo de Caso em tela, foi realizada por meio da aplicação de trinta e cinco (35) questionários para os três (03) atores do objeto da investigação. Os questionários procuraram verificar os resultados das relações existentes entre as variáveis independentes ou antecedentes no intuito analisar a mensuração das análises dos dados.

$\mathrm{Na}$ acepção de Cunha (2006, p. 01), “a avaliação é um instrumento importante para a melhoria da eficiência e eficácia do gasto público, da qualidade da gestão e do controle sobre a efetividade da ação do Estado, bem como para a divulgação de resultados de governo". Assim, os aspectos metodológicos de uma pesquisa quantitativa possuem características que permitem que os resultados possam ser medidos de forma objetiva em relação aos valores apresentados, podendo-se estimar através da investigação dos dados, as intervenções dos atores governamentais por intermédio de peritos em avaliações de características internas e externas, assim como por meio dos atores beneficiados. Deve-se ressaltar também, que a metodologia quantitativa dispõe de peculiaridades para processos de medição com objetividades acerca dos valores encontrados, havendo a possibilidade de promover estimativas por intermédio da análise dos dados das intervenções dos atores governamentais, mediante peritos especializados em avaliações internas e externas, assim como através dos demais atores e beneficiários envolvidos no processo.

Em síntese, as pesquisas de caráter quantitativo permitem o gerenciamento dos dados representativos, havendo a necessidade da apresentação de um recorte preciso do universo pesquisado. De acordo com Stevenson (1981, p. 3 apud CARVALHO, 2018, p. 133), dentre as diversas vantagens apresentadas no universo amostral "pode-se citar 
que, por envolver um número menor de dados, perde-se menos tempo na obtenção dos mesmos, menor custo operacional e exige menos coletores de dados, o que reduz as chances de erro".

A fim de compreender como esses elementos foram importantes no Estudo de Caso evidenciado, o pesquisador elaborou e aplicou questionários fechados para a obtenção dos dados empíricos de forma estruturada em três (03) partes, estando a primeira focada em abordar e conhecer o perfil social dos três atores objeto da pesquisa (professores, equipe técnica e beneficiários). A segunda parte, por sua vez, procurou conhecer e abordar a relação existente entre os referidos atores e o Pronera desenvolvido na UESB, considerando fatores de ordem social, cultural, social e econômica inerentes a cada ator. Finalmente, a terceira parte questionou aos atores sobre a forma como os mesmos avaliaram as ações de ordem pedagógica desenvolvidas no recorte temporal proposto na Pesquisa.

As análises qualitativas empregadas na pesquisa foram de caráter exploratório, com realização de entrevistas semiestruturadas. Triviños $(1987$, p. 116) afirma que a pesquisa qualitativa teve seu surgimento "na década de 70 [...] nos países da América Latina". Ainda em conformidade com o referido autor, "o ensino sempre se caracterizou pelo destaque de sua realidade qualitativa, apesar de manifestar-se frequentemente através de medições e de quantificações (porcentagens de analfabetos, do crescimento anual da matrícula, dos professores titulados e não titulados, etc.)" (IDEM, p. 116).

Tendo em vista as especificidades intrínsecas a esse tipo de abordagem, as entrevistas realizadas foram baseadas na análise de conteúdo em que Bardin (2011. P. 41) destaca que este procedimento guarda referência em

Um conjunto de técnicas de análise das comunicações visando obter, por procedimentos, sistemáticos e objetivos de descrição do conteúdo das mensagens, indicadores (quantitativos ou não) que permitam a inferência de conhecimentos relativos às condições de produção/recepção (variáveis inferidas) destas mensagens. (BARDIN, 2011, p. 41).

Para atingir o objetivo pretendido no Estudo de Caso, o pesquisador realizou três (03) entrevistas com cada grupo de atores pesquisados, estando as entrevistas gravadas, tendo duração de trinta (30) a cinquenta (50) minutos, com pleno consentimento de todos os atores pesquisados.

\section{Resultados obtidos com a pesquisa quantitativa}

As avaliações e os resultados obtidos na metodologia empregada na pesquisa quantitativa, permitiram ao pesquisador identificar de forma empírica como o ciclo das políticas públicas teve interferência direta no Pronera/UESB, notadamente, em relação ao que fora planejado, implantado e implementado, que auxiliou na fase de formulação e nas metodologias de avaliação que o Programa teve nas ações dos atores governamentais. O procedimento de avaliação de uma política pública constitui uma ferramenta importante para a mensuração dos gastos públicos através dos padrões de eficácia e eficiência obtidos.

Nesse sentido, no intuito de referendar empiricamente as colocações acima expostas, e conforme já mencionado, os questionários aplicados abordaram, no primeiro momen- 
to, questões de ordem social como sexo, escolaridade, renda mensal, faixa etária e cor/ raça. No segundo momento, quando da inquirição sobre a relação existente entre os três (03) atores pesquisados com o Pronera/UESB, foram abordados temas com teor social, cultural, econômico e político dos grupos pesquisados, englobando também o projeto pedagógico implementado, com mudanças ou não na realidade dos beneficiários, duração e horários dos cursos, metodologia empregada nas aulas e aproveitamento dos alunos através dos conhecimentos adquiridos. Em relação ao terceiro momento, foram abordadas questões inerentes à avaliação do Pronera/UESB quanto à execução das ações pedagógicas, que foram desenvolvidas no marco temporal estabelecido na Pesquisa (CARVALHO, 2018).

$\mathrm{Na}$ análise e tratamento dos dados quantitativos o pesquisador utilizou o Software IBM SSPS Statisctic ${ }^{1}$ versão 20, no sentido de os dados analisados e mensurados terem o grau de cem por cento (100\%) de certeza de confiabilidade, em conformidade com os princípios epistemológicos e filosóficos que a análise dos dados empíricos possam apresentar. A esse respeito, Carvalho (2018, p. 25) afirma que

A utilização de softwares e programas estatísticos não exime a compreensão da fala dos sujeitos e suas ações em que os mesmos se encontram e qual a função que eles desempenham na sociedade, procurando, assim, perceber a realidade cedida por esses sujeitos e pelos documentos estudados, sem perder de vista a compreensão de que essa realidade tem como determinante os contextos materiais, realizados pelos sujeitos que por sua vez, também, são determinados por eles.

Em relação ao tratamento dos dados obtidos no primeiro momento da pesquisa, o pesquisador verificou que $80 \%$ dos respondentes dos atores pesquisados são do sexo feminino e $20 \%$ do sexo masculino. Em relação ao grau de escolaridade dos atores pesquisados, todos os membros da equipe técnica e dos professores possuíam nível superior, sendo que $40 \%$ possuíam algum curso a nível de Pós-Graduação, 20\% a nível de Mestrado e $20 \%$ a nível de Doutorado. No tocante aos beneficiários (alunos), nenhum destes possuía curso de nível superior e $20 \%$ já tinham concluído o Nível Médio.

Analisando empiricamente os dados acima, observa-se a predominância dos atores do sexo feminino em relação ao masculino, ressaltando que o pesquisador observou que esta disparidade foi maior em relação aos beneficiários. Quanto à análise do grau de escolaridade dos pesquisados, com base nos dados coletados, é correto afirmar que o Pronera/UESB possuía uma equipe técnica e professores com nível de qualificação acadêmica satisfatório para um projeto de educação pública dessa envergadura.

Quando o pesquisador abordou sobre o padrão de renda mensal de cada grupo pesquisado, obteve-se os seguintes resultados: $70 \%$ informaram que não possuíam nenhum tipo de renda, $20 \%$ possuía renda mensal entre 3 e 4 salários mínimos, $10 \%$ recebiam renda mensal entre 5 e 10 salários mínimos. Estes percentuais encontrados evidenciaram que nenhum dos beneficiários (70\%) não dispunham de qualquer fonte de renda, $20 \%$ dos membros da Equipe Técnica possuía renda mensal entre 3 e 4 salários mínimos e que $10 \%$ do corpo docente possuía renda mensal entre 5 e 10 salários mínimos. 
Interpretando os dados e características obtidos junto aos pesquisados sobre a faixa etária dos mesmos, o pesquisador encontrou resultados bastante similares entre os membros da equipe técnica e dos professores, sendo que $40 \%$ possuíam idade entre 26 a 49 anos. Já entre os beneficiários, foi constatado que os mesmos possuíam idades entre 16 a 25 anos, representando $60 \%$ do tal pesquisado.

Finalizando os dados amostrais aqui representados em relação ao Estudo de Caso, foi verificado como os respondentes consideravam sua cor/raça e neste quesito, na análise empírica conjunta com os três atores analisados, $80 \%$ responderam que se consideravam pardos e $20 \%$ brancos.

A pesquisa quantitativa realizada demonstrou empiricamente a existência de algumas lacunas e limites existentes no Pronera e na execução do Programa pela UESB, considerando os avanços dele em consonância com as práticas pedagógicas aplicadas, $\mathrm{o}$ caráter epistemológico existente e o papel da equipe técnica, professores e dos beneficiários (alunos) que concluíram os cursos conveniados.

Constatou-se na pesquisa, que a realização dos cursos do Pronera/UESB promoveu, de forma afirmativa, um redimensionamento de caráter afirmativo nas práticas acadêmicas e pedagógicas dos discentes beneficiados com o Programa. A pesquisa quantitativa apontou também algumas deficiências de ordem pedagógica e curricular no Programa em relação às disciplinas que viessem a despertar o conhecimento mais apurado e a análise crítica dos alunos, no tocante às relações de poder na sociedade capitalista. Também foram apontadas deficiências na gestão do Programa, tanto no acompanhamento dos discentes egressos no pós-curso, quanto ao desenvolvimento das suas atividades acadêmicas e profissionais.

A respeito da decomposição das variáveis analisadas em relação ao segundo momento da pesquisa quantitativa, o pesquisador procurou ressaltar e evidenciar os resultados encontrados nas suas determinações e implicações a partir de uma análise em conjunto, conforme os temas assinalados anteriormente. Assim, na realização das inquirições acerca dos temas propostos, ficou evidenciado que o Projeto Pedagógico proposto pelos atores UESB, dos movimentos sociais e sindicais parceiros nos convênios e aprovado pelos atores INCRA e Pronera (através da CPN) atendeu, quase que em sua totalidade, os pontos elencados nesta etapa do Estudo de Caso. O Projeto Pedagógico executado procurou contemplar os anseios e ações de todos estes atores em determinado período de tempo (2004/2013), estabelecendo quais objetivos os sujeitos (atores) deveriam focar-se em prol da excelência que deve pautar o modelo adequado de ensino-aprendizagem por meio das metas curriculares a serem alcançadas.

Analisando as definições fornecidas, a pesquisa quantitativa comprovou que os respondentes aprovaram que o Projeto Pedagógico atendeu consideravelmente os parâmetros de ordem social, cultural e político que foram propostos, sendo evidenciado na concordância e aprovação uníssona dos respondentes em relação ao Projeto Pedagógico executado, em conformidade com a metodologia empregada nas aulas, aproveitamento dos livros didático dos alunos e duração e horários dos cursos, conforme foi demonstrado no Gráfico 1. 
Gráfico 01 - Parâmetros norteadores do Projeto Pedagógico

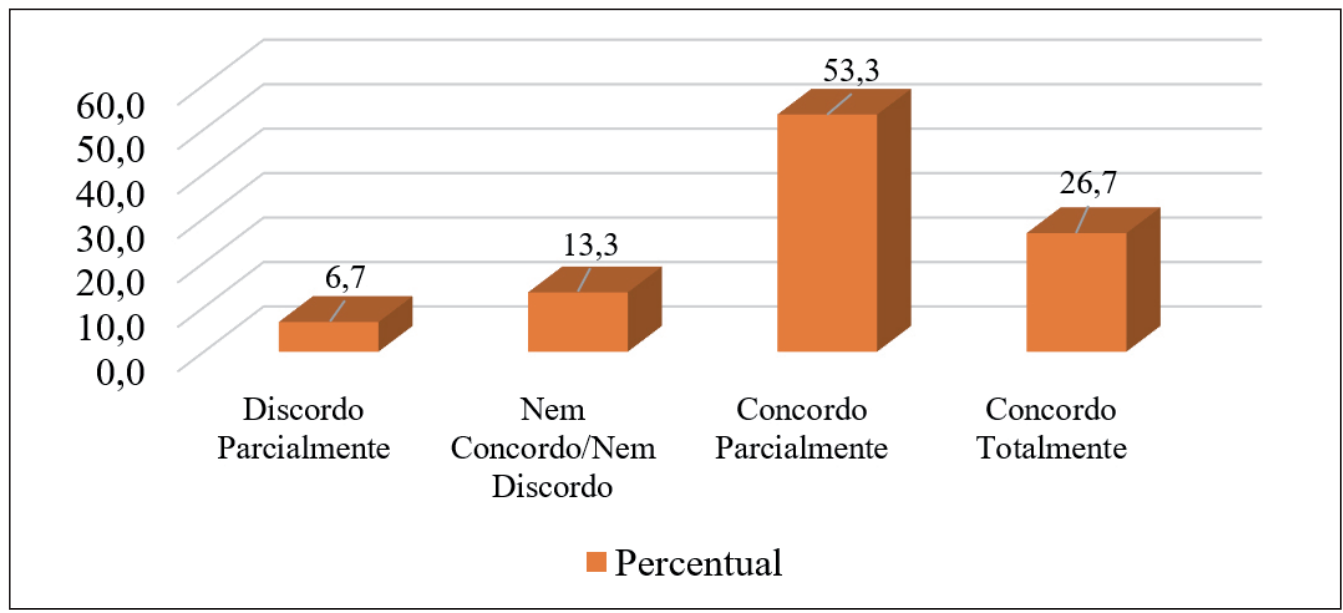

Fonte: Autoria própria, 2018.

Ainda com relação ao Projeto Pedagógico, o pesquisador perguntou se o mesmo poderia contribuir para mudanças na realidade social dos beneficiários em suas localidades de origem. Entre os percentuais respondidos, $60 \%$ informaram que concordavam parcialmente, $26,66 \%$ não concordavam nem discordavam e somente $13,34 \%$ concordavam totalmente. Estes dados encontrados podem revelar e evidenciar aspectos que podem ser melhor compreendidos por meio de algumas categorias do $\mathrm{MDH}$ aqui expostas, sobretudo a contradição, na medida em que os cursos do Pronera realizados pela UESB, traduzidos em políticas públicas educacionais, deveriam retratar e materializar as lutas dos sujeitos do campo por condições melhores de vida e dignidade representadas neste modelo de política pública.

As análises realizadas demonstram o fato de que o Pronera, representa e consolida-se como projeto de políticas públicas pioneiro no oferecimento de educação para os povos do campo, buscando melhorar os indicativos de educação, a pesquisa demostrou que essa política de educação realizada na UESB cumpriu de maneira parcial e tênue a sua função social junto aos alunos egressos, no sentido de que estes possuíssem determinadas condições objetivas de complexificar e promover alterações sociais nas localidades em que se originaram, em conformidade com suas realidades (SANTOS; SILVA, 2017).

Dessa forma e sob tal complexidade, o projeto de educação do campo desenvolvido na UESB cumpriu de forma satisfatória os pressupostos elencados no seu Projeto Pedagógico, em relação à transmissão dos conhecimentos acadêmicos necessários ao preparo dos educandos para ingresso na vida profissional e posterior avanço na vida acadêmica, porém, cumpriu de forma parcial a transmissão dos conhecimentos e saberes elementares para que esses educandos egressos pudessem ter uma formação crítica adequada. Desta maneira, os educandos puderam compreender de forma insipiente como as relações do sistema capitalista influenciam em uma totalidade social, política e econômica em consonância com a universalidade, particularidade e singularidade do sistema vigente, que poderia contribuir para a elevação do grau de consciência individual e coletiva dos educandos, reverberando em suas localidades de origem através do entendimento das relações de contradição proposta pelo MHD, na medida que 
A superação da fragmentação do saber e de uma aprendizagem mecânica, que conduzem à formação de alunos passivos, reprodutores de conhecimentos prontos e acabados, transmitidos pelo educador. O que se promove é uma ação-reflexão-ação, que dê sentido ao processo educativo escolar, superando o pragmatismo, a força do fazer e redescobrindo a importância do educador como mediador do processo de construção do conhecimento em uma perspectiva sistêmica e integrativa, em que o pensar e o agir estejam sustentados em uma visão de projeto pedagógico que assuma as diretrizes do ensino problêmico. (PEREIRA; SANTOS, 2012, p. 160-61).

No terceiro momento da inquirição realizada pelo pesquisador, fez-se necessário obter as impressões dos atores em relação à avaliação que os mesmos poderiam fazer no tocante à execução do Programa na Instituição alvo da Pesquisa, em conformidade com o marco temporal estabelecido. Todos os atores pesquisados foram unânimes em afirmar o êxito do Programa, relacionado à transmissão, por parte dos docentes, e a efetiva apreensão dos conteúdos das disciplinas ministradas por parte dos alunos, referendando o que fora apresentado anteriormente em relação ao Projeto Pedagógico executado, no que se refere à concordância dos pressupostos didáticos e acadêmicos definidos na grade curricular de cada curso executado.

Portanto, há que se considerar, para além das análises propositivas e afirmativas em relação ao Projeto Pedagógico, que os três (03) grupos investigados foram praticamente unânimes $(80 \%)$ em afirmar que as aulas dos cursos realizados no recorte temporal pesquisado abordaram, de forma muito superficial, as questões envolvendo as relações de poder na sociedade capitalista e a falta de acompanhamento, por parte da UESB, de aspectos da vida educacional, social e econômica dos alunos egressos.

Isto nos leva a observar o que os dois pontos "anteriormente" citados, constituíram-se um entrave social e político grave ao pleno desenvolvimento de um Programa de educação no campo desenvolvido na IES pesquisada, em parceria com os demais atores, notadamente os movimentos sociais e sindicais, na medida em que o Programa poderia, de forma isenta, ressaltar a importância e protagonismo desses movimentos, estes, que sempre suscitaram propostas para implantação e implementação de políticas públicas com novas práticas e viés democrático, pautados em uma educação para o campo. Poder-se-ia abordar temas e proposições que pudessem ressaltar essas relações de poder na sociedade e suas implicações diretas no contexto social, político e ideológico, demostrando como essa política de educação do campo foi implementada e efetivamente consolidada por intermédio dos embates e contradições existentes na sociedade capitalista.

Quanto ao acompanhamento dos educandos no pós curso, foi comprovado nos dados analisados no Estudo de Caso que a Universidade não dispunha de nenhum mecanismo pedagógico e/ou administrativo de acompanhamento e avaliação dos beneficiários egressos, implicando diretamente na deficiência dos instrumentos de gestão da UESB em acompanhar a atuação acadêmica e profissional desses alunos, bem como verificar se os mesmos desenvolveram ou não competências e instrumentos para empreenderem mudanças em seus locais de origem. 


\section{Resultados obtidos com a análise qualitativa}

Com relação à pesquisa de caráter qualitativo, o pesquisador realizou entrevistas semiestruturadas com os atores envolvidos, no sentido de proceder um aprofundamento desses sujeitos em questões que tivessem relação direta com o universo do Programa na Instituição alvo da pesquisa.

Procurando realizar uma coleta de dados que referendasse as entrevistas semiestruturas em conformidade com os pressupostos inerentes a um Estudo de Caso, o pesquisador empregou os conceitos de Triviños (1987) de acordo com as seguintes considerações

Podemos entender por entrevista semiestruturada, em geral, aquela que parte de certos questionamentos básicos, apoiados em teorias e hipóteses, que interessam à pesquisa, e que, em seguida, oferecem amplo campo de interrogativas, fruto de novas hipóteses que vão surgindo à medida que se recebem as respostas do informante. Desta maneira, o informante, seguindo espontaneamente a linha de seu pensamento e de suas experiências dentro do foco principal colocado pelo investigador, começa a participar da elaboração do conteúdo da pesquisa (TRIVIÑOS, 1987, p. 146).

As entrevistas tiveram como objetivo verificar posicionamentos, avaliações e contradições apontadas pelos sujeitos pesquisados, no intuito de pautar os avanços, contrapontos e possíveis antagonismos no modelo de ensino proposto em consonância com os contrastes estabelecidos na totalidade das relações sociais, governamentais e políticas em conformidade com os relatos dos entrevistados.

Após a obtenção dos dados, foram identificados os aspectos temáticos mais relevantes por categorias para o Estudo de Caso, com o objetivo de sistematizar estes aspectos para realização de análises relativas à avaliação do Programa como política pública, percepções dos atores sobre a implementação do Programa na Instituição estudada, e se o Pronera/UESB representou um instrumento mobilizador que proporcionou que os educandos pudessem entender e reduzir os níveis de alienação, em relação às questões sociais através do processo educativo a que se submeteram.

Sobre a análise e tratamento das entrevistas, o pesquisador adotou nomes fictícios representados por letras, ressaltando a premissa da manutenção do sigilo dos entrevistados e facilitação da organização e categorização das informações obtidas. Dessa forma, foi inquirido aos entrevistados sobre a avaliação e implementação do Pronera/ UESB como política pública do Governo Federal. Carvalho (2018, p. 168) infere que um dos entrevistados respondeu:

Acho que é uma política pública interessante e necessária, uma vez que visa acompanhar um grupo específico, que é o grupo de reforma agrária que historicamente está excluído das oportunidades sociais, sejam elas relacionadas à educação, saúde, lazer e conhecimento técnico e acadêmico, então é um programa que visa a formação profissional e técnica para esse grupo específico, de tamanha importância. (MEMBRO DA EQUIPE TÉCNICA W, 2018).

Confirmando as proposições do entrevistado "W", os demais respondentes seguiram a mesma linha de análise, ou seja, reconheceram e referendaram a importância do Pro- 
grama no rol das políticas públicas, destacando que o mesmo surgiu das lutas e das pressões dos movimentos sociais organizados como sociedade civil, a favor de uma gama de sujeitos (jovens e adultos) do campo marginalizados e excluídos e impossibilitados de ingressarem em uma metodologia educacional de qualidade.

A partir das inferências dos entrevistados, pode-se afirmar que o Programa atendeu e proporcionou as garantias e os direitos a uma população jovem e adulta do campo, carente de acessar cursos de Nível Médio Integrado ao Técnico em uma instituição pública pelas vias do Estado que deve procurar fomentar e cumprir seu papel constitucional para a oferta de um serviço público essencial como a educação.

O Programa atendeu um grande número de educandos oriundos do campo e representou a principal fonte de oferta para cursos dessa natureza em várias modalidades de ensino, propiciando que estes educandos viessem a ampliar suas potencialidades intelectuais, com reflexo direto na vida profissional de muitos destes que tiveram sua inserção no mundo do trabalho, para além das relações manifestadas pelo sistema do capital.

Em um quadro destes, pode-se inferir que a materialização do Pronera/UESB estabelece importante propulsor para a educação do campo historicamente excluída do direito à educação, a partir do momento em que uma Universidade Pública concretiza uma parceria com os movimentos sociais e sindicais, para execução de uma política pública conduzida pelos atores governamentais a nível federal na arena de disputas intrínsecas ao sistema capitalista. Desse modo, a categoria totalidade do MHD pode exprimir a relação direta existente entre o Programa e as relações intrínsecas entre todos os atores envolvidos no processo, na medida em que a totalidade como prática social demonstrou os tipos de relações contraditórias no modelo de produção do saber na sociedade capitalista, em que o Programa intentou romper com determinismos sociais, educacionais e políticos que atuam e alimentam de forma direta e indireta no modelo de reprodução ideológico que governa o sistema capitalista no país. Desse modo, a categoria totalidade é compreendida também nesse processo como uma realidade objetiva, em coerência com os elementos que caracterizam as relações concretas em suas determinações, na qual, o Programa referenda-se como componente de uma totalidade do Estado capitalista concreta, advinda de uma proposta que se materializou em uma política pública singular para a manutenção de reciprocidade entre a parte e o todo (LUKÁCS, 1967).

Finalizando o rol de entrevistas, em conformidade com o grau de relevância proposto para apresentação deste Estudo de Caso, o pesquisador inquiriu aos entrevistados se o Pronera/UESB constituiu um instrumento mobilizador, que pudesse gerar contribuição para redução dos níveis de alienação educacional desses sujeitos do campo atendidos pelo Programa em consonância com a proposta pedagógica de cada curso. Foram obtidas as seguintes respostas:

Sim. O Pronera proporciona aos seus beneficiários a aprendizagem formal que propicia ao ser social vislumbrar novos horizontes para além dos conhecimentos acadêmicos adquiridos. De certo modo, pode contribuir para a redução dos níveis de alienação impostos pela sociedade em que vivemos. (PROFESSOR L, 2018).

Pode-se afirmar que sim. Os cursos do Pronera possibilitam sim esse instrumento, na medida em que eleva o nível educacional dos sujeitos atendidos, de 
acordo com suas carências educacionais e culturais. (MEMBRO DA EQUIPE TÉCNICA Z, 2018).

Sim, pois leva a educação a um público pouco favorecido, que muitas vezes, não teria condições de fazer uma alfabetização, um curso de Ensino Médio. O processo educativo, seja ele qual for, propicia à pessoa uma visão de mundo diferenciada, entendendo com maior clareza o que ocorre nas relações sociais. (BENEFICIÁRIO R 2018).

Diante das respostas apresentadas, pode-se perceber que os entrevistados tiveram unicidade nas respostas em relação às afirmativas propostas, em relação ao que foi apresentado. Os atores respondentes tiveram a compreensão de que os sujeitos beneficiados com o Programa tiveram, de certo modo e de forma superficial, percepções no seu processo formativo que pudessem influenciar de maneira afirmativa nas suas identidades como sujeitos oriundos do campo, para que conseguissem entender aspectos alienantes na educação acadêmica formal, mesmo que essas percepções não fossem postas em prática por meio da ação de mobilização interna e externa desses sujeitos.

As pesquisas de ordem qualitativa tiveram como objetivo responder, de forma incontestável, questionamentos apresentados como objetivos singulares relacionados ao Estudo de Caso, objetivando verificar as percepções dos três (03) atores que participaram diretamente na execução do Programa. Como principais constatações dos atores entrevistados, pode-se evidenciar o fato de que os discentes não adquiriram competências nos cursos ministrados que pudessem contribuir para ações proativas e mudar a realidade social de suas localidades de origem. Os entrevistados afirmaram que o Programa não dispunha de instrumentos pedagógicos e administrativos (de gestão) para o acompanhamento de transformações sociais, culturais e econômicas ocorridas na vida dos beneficiários egressos, assim como não possuía instrumentos capazes de verificar e acompanhar a atuação dos alunos egressos em relação a suas vidas acadêmicas e profissionais.

Em concordância com a análise acima exposta, Marx (2004, p. 81) cita que “[...] o burguês entende por educação [...] a memorização dos princípios burgueses, e que no fim das contas a burguesia não tem os meios, nem vontade, de oferecer ao povo uma verdadeira educação". Corroborando com esta afirmativa, deve-se salientar que o Estado capitalista estabelece ações teóricas e práticas para a obtenção de conhecimentos a docentes e educandos por dentro das estruturas já estabelecidas a favor do sistema educacional existente no país, impossibilitando, de certa maneira, que eventuais potencialidades e atitudes de educadores e discentes possam ser expressas em outras direções sociais que não seja o educandário.

Nesse âmbito da análise realizada, de acordo com Carvalho (2018), pode-se afirmar que o Programa, segundo as condições objetivas postas em prática, vem promovendo, de certo procedimento, o enfrentamento e rompimento com a lógica alienante do modo de produção das relações capitalistas em um sistema educacional público por dentro da lógica mercadológica da educação privada, em que o sistema educacional implementado contribui para que os alunos não adquiram os conhecimentos básicos que possam pôr em prática em suas relações sociais. 


\section{Considerações finais}

Procurou-se com o presente recorte textual, entender a importância da necessidade de investigação e execução do Pronera como programa de política pública educacional de educação do campo em uma universidade pública, programa este, do Governo Federal. A investigação teve como foco as percepções dos principais atores partícipes da Pesquisa (equipe técnica, professores e beneficiários), no período compreendido entre 2004 a 2013. As análises tiveram como seu suporte algumas categorias do referencial teórico do MHD, visto que esta política pública não foi implementada em conformação direta pelos atores governamentais, sem a existência de contradições derivadas de embates realizados pelos atores (sujeitos) dos movimentos sociais, em um mecanismo permeado por disputas por lutas com especificidade social, política e econômica.

O pesquisador optou pelo método de Estudo de Caso, com objetivo de compreender e analisar os diversos aspectos relativos à percepção relacionados com a concepção, implantação e implementação desse Programa na Universidade alvo da pesquisa e como se deu sua inserção na arena das políticas públicas do Estado capitalista. A realização de pesquisas de caráter quantitativo e qualitativo proporcionou ao pesquisador a percepção da complexidade dos fenômenos relacionados ao ciclo das políticas públicas, Redes de Políticas Públicas do Pronera/UESB como política educacional direcionada para o campo e a função desempenhada pelos atores (governamentais e não governamentais) que participaram direta e/ou indiretamente do processo.

A concepção, implementação e execução desse Programa na UESB, por parte de todos os atores envolvidos, propiciou que um projeto de educação formal alcançasse sujeitos do campo historicamente excluídos de acesso a uma educação pública e de qualidade, que viesse a suprir suas demandas em relação ao aprendizado acadêmico, como também, promover a humanização desses sujeitos por meio das teorias, prática e saberes adquiridos nos cursos ministrados.

O Estudo de Caso demonstrou que o Pronera/UESB, como política educacional, contribuiu de maneira ostensiva para a capacitação e formação dos atores oriundos do campo, por intermédio da constituição dos princípios acadêmicos e profissionais no transcorrer do desenvolvimento histórico do Programa, através da modalidade de ensino-aprendizagem proposta. O Estudo de Caso e os resultados das pesquisas realizadas demostraram também que o ciclo das políticas públicas representou uma concepção teórica e prática, que permitiu a análise de forma mais complexa do entendimento de uma política pública específica como o Pronera/UESB, em que foram destacadas as relações e inter-relações incluídas nos cenários macro e micro e os atores governamentais que estabelecem essas relações de maneira horizontal, vertical, direta e linear decorrentes do contexto social resultantes do modelo de política de educação do campo.

A pesquisa demonstrou ainda que essa política pública de educação do campo implementada na UESB, consentiu em tornar evidente o protagonismo de todos os atores (governamentais) propriamente envolvidos na pesquisa, assim como os membros da sociedade civil organizada nos movimentos sociais e sindicais (não governamentais) que propuseram políticas públicas em prol de uma nova percepção educacional, ordenada no viés democrático do campo. Outro aspecto apontado na pesquisa, sobretudo a quan- 
titativa, exprimiu a presença de lacunas e limites que existiram no Programa executado na UESB no recorte temporal objeto do Estudo de Caso, onde ficaram evidenciados os avanços obtidos em conformidade com as práticas pedagógicas empreendidas, bem como o caráter epistemológico presente em relação ao papel desenvolvido pelos membros da equipe técnica, docentes e discentes que contribuíram efetivamente para que os cursos conveniados fossem concluídos.

A pesquisa constatou também que os atores diretamente envolvidos na execução dos cursos do Pronera na Instituição alvo de estudo promoveram, de forma assertiva, um redimensionamento de cunho afirmativo nas ações pedagógicas dos alunos beneficiários que concluíram os cursos. Por outro lado, as análises realizadas em relação à pesquisa quantitativa ratificou a presença de limitações de ordem curricular e pedagógica no Programa relacionadas à inexistência de disciplinas que resultassem no despertar e na compreensão dos discentes para que pudessem realizar, mesmo que de forma superficial, análises críticas relacionadas à sociedade capitalista nas suas relações de poder social, político, cultural e econômico. Corroborando com as limitações acima descritas, foram observadas e constatadas, também na pesquisa quantitativa, deficiências de ordem pedagógica e administrativa no Programa, relacionadas ao acompanhamento por parte da UESB e a equipe gestora do Programa dos beneficiários egressos relacionadas ao desenvolvimento de atividades profissionais e acadêmicas no pós-curso.

Dentro desta ótica, observando as constatações realizadas até este ponto, a análise na perspectiva das categorias "singularidade" e "universalidade" do MHD permite evidenciar o caráter epistêmico em consonância com as relações sociais e políticas travadas entre os atores envolvidos diretamente no Programa, incluindo a presença dos movimentos sociais e sindicais parceiros e a sociedade capitalista, caracterizada pelos atores governamentais e suas instâncias representativas. Para compreensão e entendimento da categoria singularidade, relacionada ao Pronera como política pública de educação do campo, mister se faz a assimilação de que as reflexões e os ideais que prevalecem relativamente aos atores implicados no Programa possam auferir modelos que possam aproximar-se das condições objetivas e das etapas que guardam relação direta com o grau de particularidade do Programa, caracterizada pelos atores e instâncias governamentais e sua política específica para o projeto de educação do campo.

Por seu turno, a categoria universalidade foi representada nesta pesquisa pelo Estado com suas relações sociais capitalistas por intermédio de seus atores governamentais e suas consequentes necessidades através dos embates de classes e estas estão também inseridas na singularidade representativa desta pesquisa. Paralelamente, a categoria particularidade na pesquisa representa a conexão existente entre a universalidade e a singularidade, traduzida na política de educação do campo materializada e interposta no procedimento de mediação existente, ou melhor, o particular.

Dentro dessa perspectiva, os resultados das pesquisas quantitativa e qualitativa comprovaram que os atores (beneficiários), oriundos de uma realidade campesina, puderam se mostrar como sujeitos (atores) principais do Estudo de Caso e que se apresentaram com suas histórias e vivências adquiridas, em que a grande maioria vislumbrava com o Programa, não só a aquisição dos conhecimentos acadêmicos e pedagógicos inerentes a cada curso ministrado, como também buscavam adquirir conhecimentos básicos re- 
lativos a determinadas questões de ordem social, política, cultural e econômica que pudessem auxiliar para vislumbrar possíveis transformações em suas realidades de vida, bem como de suas localidades de origem. A constatação deste fato vai de encontro com os preceitos críticos, teóricos e práticos que deveriam nortear o Projeto Pedagógico e a grade curricular do Programa, advindos das experiências e embates dos movimentos sociais e sindicais parceiros nos projetos conveniados, no sentido de que poderia munir os beneficiários com determinados conhecimentos intrínsecos à proposta metodológica do Programa e a ordem social vigente para que os mesmos pudessem entender e aplicar na convivência com seus pares em ações contra hegemônicas típicas do sistema capitalista.

Torna-se significativo considerar que o Programa não realizou, em sua essência, o seu processo de formação social e o despertar das potencialidades dos alunos em relação à concepção dialética pautada e evidenciada, mas podemos concluir que isto se deve às contradições demonstradas no contexto social e político do país, que são reverberadas nas políticas educacionais do campo, por meio da correlação de forças estabelecidas entre os movimentos sociais que representam os trabalhadores; e o agronegócio representado pelos latifundiários e o Estado capitalista. Como saldo positivo, temos políticas importantes como o Pronera que contribuem para minimização das desigualdades sociais à medida que proporcionam uma educação do campo para os filhos dos camponeses.

\section{Referências}

AZEVEDO, Janete Maria Lins de. A Educação como Política Pública. Campinas: Autores Associados, 2004.

BARDIN, Laurence. Análise de Conteúdo. São Paulo: Edições 70, 2011.

BRASIL. Portaria $n^{\circ} 10$ de 16 de abril de 1998. Publicada no DOU nº 77, de 24/04/1998 e no BS n 17 , de 27/04/1998.

BRASIL. Ministério do Desenvolvimento Agrário, Instituto Nacional de Colonização e Reforma Agrária, Programa Nacional de Educação na Reforma Agrária. Manual de Operações 2001. Brasília, 2001b.

CARVALHO, Mauro dos Santos et al. Análise de redes de políticas públicas na Educação do Campo: uso do framework i star. Seminário Gepráxis, Vitória da Conquista/Bahia, Brasil, v. 6, nº 6, p 2837-2854, 2017.

CARVALHO Percepções da equipe técnica, dos professores e dos beneficiários sobre a gestão do Pronera no período de 2004 a 2013: o caso da UESB. Vitória da Conquista, 2018.

CHASIN, José. Método dialético. Aulas ministradas durante o curso de Pós-Graduação em Filosofia Política, promovido pelo Departamento de Filosofia e História da Universidade Federal de Alagoas, de 25/01 a 06/02 de 1988. Disponível em: <http://orientacaomarxista.blogspot.com.br/2010/10/metodo-dialetico-jose-chasin.html $>$. Acesso em: 15 out. 2017.

CUNHA, Carla Giane Soares da. Avaliação de Políticas Públicas e Programas Governamentais: tendências recentes e experiências no Brasil. Trabalho elaborado durante o curso "The Theory and Operation of a Modern National Economy",ministrado na George Washington University, no âmbito do Programa Minerva, 2006.

HERMINE, Ivan Barbosa. Iniciação ao estudo do materialismo dialético: o pensamento dialético. São Paulo, 2013.

INCRA. Instituto Nacional de Colonização e Reforma Agrária. PRONERA: Manual de Operações. Brasília, 2004.

INCRA. História do Pronera. Disponível em http://www.incra.gov.br/pronerahistoria. Acessado em $23 / 11 / 2016$. 
LUKÁCS, Georg. Ontología del ser social: el trabajo. Traducción de Antonino Infranca e Miguel Vedda. Buenos Aires: Herramienta, 2004.

LUKÁCS Existencialismo ou marxismo. São Paulo: Senzala, 1967. In: CARVALHO, Edmilson. A Totalidade como Categoria Central na Dialética Marxista. Instituto de Estudos Socialistas, nº 15, 2007.

LUKÁCS. Prolegômenos para uma ontologia do ser social: questões de princípios para uma ontologia hoje tornada possível. In: MASSON, G. As contribuições do método materialista histórico e dialético para a pesquisa sobre políticas públicas. IX Seminário de Pesquisa e Educação da Região Sul. Caxias do Sul/RS, 2012.

MARX, Karl. Manuscritos econômicos filosóficos. São Paulo: Boitempo, 2004.

MOLINA, Mônica Catagna. Brasil. Ministério do Desenvolvimento Agrário. Educação do Campo e Pesquisas: questões para reflexão. Brasília: Ministério do Desenvolvimento Agrário, 152 p., 2006.

PEREIRA, Lúcio Alves; SANTOS, Roseli Bernardo Silva dos. Uma experiência do campo: o enfoque materialista histórico-dialético em sala de aula. In: GHEDIN, Evandro. Educação do Campo: epistemologia e práticas. 1. ed. São Paulo: Cortez, 2012.

PETERS, B. G. American public policy. Chatham, N.J.: Chatham House, 1986.

SANTOS, Dayna Mara Sanches.; SILVA, Neylson Oliveira da. Educação na Reforma Agrária: a experiência do PRONERA e os 19 anos de luta e revolução. Universidade Federal do Recôncavo Baiano (UFRB). Universidade Federal do Maranhão (UFMA), 2017.

STEVENSON, William J. Estatística Aplicada à Administração. Trad. Alfredo Alves de Farias. São Paulo: Ed. Harper e Row do Brasil, 1981.

TRIVIÑOS, Augusto Nibaldo Silva. Introdução à Pesquisa em Ciências Sociais: a pesquisa qualitativa em educação. São Paulo: Atlas, 1987.

\section{Sobre autores}

\section{Arlete Ramos dos Santos}

Pós-doutorado em educação e movimentos sociais (UNESP), doutora e mestre em educação pela FAE/ UFMG; Profa. Adjunta da UESB; Porfa. do PPGE/UESC e do PPGED/UESB.

\section{Mauro dos Santos Carvalho}

Mestre em Educação pela Universidade Estadual do Sudoeste da Bahia (UESB), Especialista em Qualidade Total na Agricultura Empresarial pela Universidade Federal de Lavras (UFLA), graduado em Ciências Econômicas pela Universidade Federal da Bahia (UFBA), Servidor Efetivo da Universidade Estadual do Sudoeste da Bahia (UESB), membro do Grupo de Estudo e Pesquisa em Política Educacional em Educação do Campo (GEPEMDEC) na UESB e membro do Grupo de Estudos e Pesquisa sobre Educação no Campo na Universidade Estadual 
